\title{
Labyrinthe
}

$8 \mid 2001$

Numéro 8

\section{Le garçon, le boeuf et le marché. Une image du changement en Afrique sub-saharienne.}

Pour des raisons techniques indépendantes de notre volonté, la mise en ligne de ce texte (et de l'iconographie qui l'accompagne) est malheureusement retardée. Elle sera effectuée dès que possible.

\section{Géraud Magrin}

\section{(2) OpenEdition}

12 Journals

Electronic version

URL: http://journals.openedition.org/labyrinthe/884

DOI: $10.4000 /$ labyrinthe. 884

ISSN: 1950-6031

\section{Publisher}

Hermann

\section{Printed version}

Date of publication: 1 January 2001

Number of pages: 83-88

\section{Electronic reference}

Géraud Magrin, « Le garçon, le boeuf et le marché. Une image du changement en Afrique sub-

saharienne. », Labyrinthe [Online], 8 | 2001, Online since 19 June 2005, connection on 01 May 2019.

URL : http://journals.openedition.org/labyrinthe/884; DOI : 10.4000/labyrinthe.884

This text was automatically generated on 1 May 2019.

Propriété intellectuelle 
Le garçon, le boeuf et le marché. Une image du changement en Afrique subsaharienne.

Pour des raisons techniques indépendantes de notre volonté, la mise en ligne de ce texte (et de l'iconographie qui l'accompagne) est malheureusement retardée. Elle sera effectuée dès que possible.

Géraud Magrin 